\title{
Living architecture and biological dispersal
}

\author{
Reid R. Coffman ${ }^{1}$, Sara Cech $^{2}$ and Roger Gettig ${ }^{3}$ \\ ${ }^{1}$ Associate Professor, Kent State University, College of Architecture and Environmental Design, \\ rcoffma4@kent.edu \\ ${ }^{2}$ Natural Resource Manager, Nature Center at Shaker Lakes \\ ${ }^{3}$ Director of Horticulture and Conservation, The Holden Arboretum
}

Coffman, R.R., Cech, S. \& Getting, R., 2014. Living architecture and biological dispersal. Journal of Living Architecture. 1(5): 1-9.

http://greenroofs.org/resources/JOLA2014Volume1(Issue5)Coffman(etal).pdf 


\begin{abstract}
Many vegetative roof systems deliver biodiversity and conservation goals, but it may be less appreciated that roofs function as a nursery, exporting biological materials. Interestingly, we have observed one green roof performing two forms of plant dispersal, thus demonstrating the potential for vegetative roofs to offer nursery services to their surroundings. We describe the project, explain the dispersal strategies, provide a brief discussion, and define the terminology of terrestrial-roof link, agent dispersal, and self dispersal, in an effort to aid in understanding the nursery function of green roofs. Continuing and future research on the dispersal mechanisms of the roof are also briefly discussed.
\end{abstract}

Key words: dispersal, nursery, source, green roof

\title{
Urban ecology and conservation
}

In traditional restoration literature human agency is often perceived as devaluation in ecosystem authenticity because natural biological processes are managed as a technological fix (Meffe and Carroll 1996). This viewpoint might be impractical in the field of urban ecological restoration, where human dominance strongly influences biological material flows and ecosystem processing. In response, new visions in the sciences (Pickett et al. 2011) and design (Waldhiem 2006, Mostafavi and Doherty 2010) are emerging that investigate the role of human facilitation in urban ecosystem performance. To examine these visions Filson and Pickett (2005) advocate initiating designs that experiment with ecological conditions in human dominated settings. Because of the rarity of natural habitats found in the urban setting, vegetative roofing is a viable mechanism that lends itself to ecological study in a format that can examine the synthetic relationships between humans and nature.

Ecosystem services provided by green roofs have been identified by many (Oberndorfer 2007, Wolf and Lundholm 2008, Coffman and Waite 2011, and Rowe 2012), however, the full spectrum of ecological functioning may be underestimated. When it comes to green roofs for biological diversity, current trends target recruitment and extension of terrestrial habitat (Brenneisen, 2006, City of Toronto 2013). Swiss biodiversity practices demonstrating high levels of plant and animal recruitment (Brenneisen, 2006) have led to biodiversity action plans in London that deliver foraging habitat for black redstarts, Phoenicurus ochruros (Grant 2006). In North America, the City of Toronto's recent guidelines reinforce the extension of terrestrial habitat from a roof's surrounding natural heritage system to include re-created, or modeled native ecosystems like prairies, alvars and fens (City of Toronto 2013). These roofs intend to offer foraging, breeding and nesting opportunities by expanding adjacent ecosystems. 
As these initiatives gain success, there is a greater need to understand how green roofs foster, or generate, biological exportation to nearby terrestrial environments. By understanding which organisms migrate from a green roof, researchers and practitioners may better develop more holistic plans and practices for roof greening.

\section{Nursery function in a green roof}

An informal experiment that installed native plants on a green roof now shows the dispersal of biological content to nearby terrestrial environments. The Nature Center at Shaker Lakes (NCSL), Shaker Heights, Ohio USA is an urban forest nature center providing conservation and community education to local citizens and has been recognized by the National Park Service, the Audubon Society and the National Wildlife Society for its commitment to stewarding high quality habitat. In continued fulfillment of its mission, a green roof was added to a portion of the first floor roof to provide additional habitat.

In 2003, twenty-three 2' x 4' (61 cm x $122 \mathrm{~cm})$ containers covering $184 \mathrm{ft}^{2}\left(17.1 \mathrm{~m}^{2}\right)$ (Green Grid $^{\circledR}$, Weston Solutions, Chicago, IL) were placed in a partial shade location on the eaves of the nature center. The trays were 8 " $(20.3 \mathrm{~cm})$ in depth consisting of engineered growing media $\left(\right.$ Green Grid $\left.^{\circledR}\right)$. Native plant species were installed as plugs in a random layout (Table 1). These natives were untested in green roofs at the time but were selected for likely success in shallow soils and partial shade conditions. The native plants grew into a robust community (Figure 1) while only receiving annual weeding maintenance, but no fertilizer or irrigation.

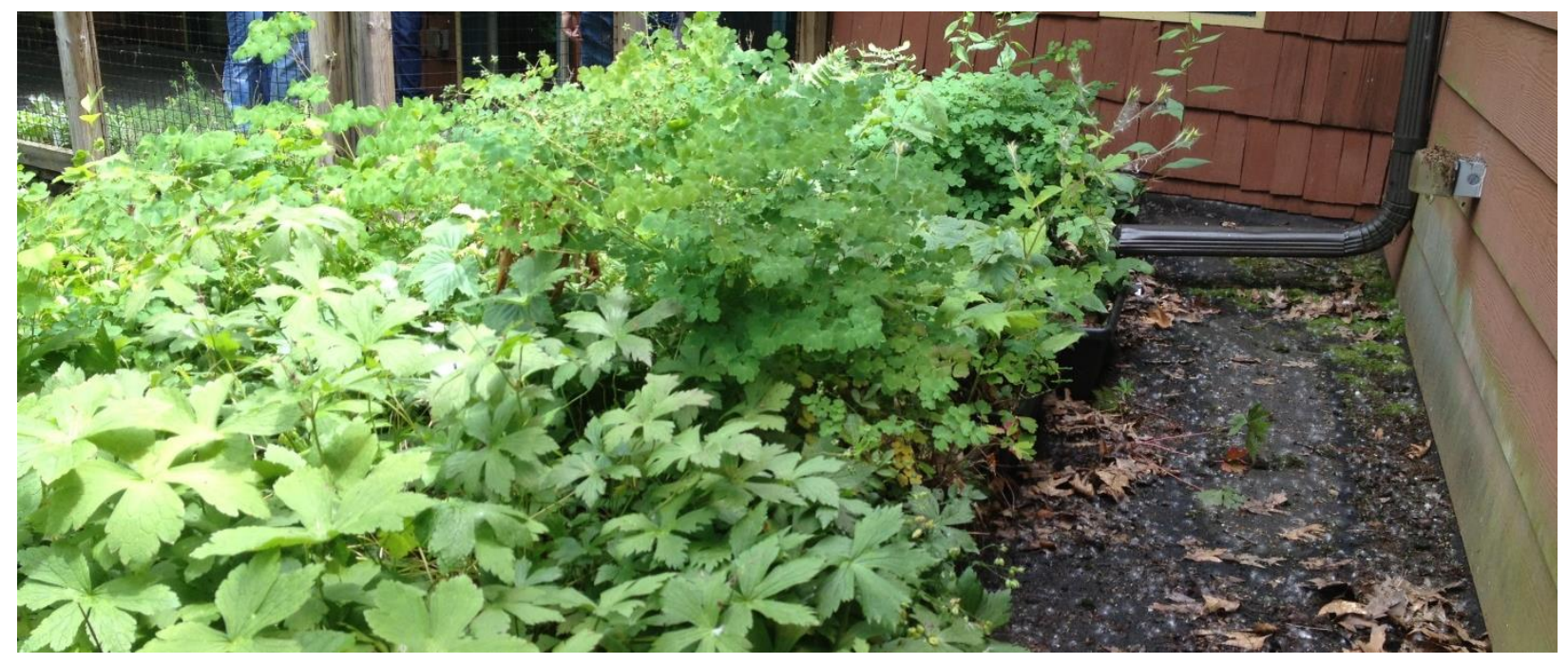

Figure 1: Image showing part of the roof trays containing Geranium maculatum and Aquilegia canadensis, two species which have dispersed to the terrestrial environment (The Nature Center at Shaker Lakes, Shaker Heights, Ohio, USA.) 
In 2011, NCSL staff observed that several species were beginning to dominate the roof. As a practical ad-hoc technique, it was decided to incorporate them into the landscape management strategy. The dominant species were relocated to terrestrial reception sites in the surrounding forest (Figure 2). Individuals of Geranium maculatum and Sporobolus heterolepis were transplanted by hand from the roof to a nearby entry path that was experiencing soil erosion. The next year, after observing success from the first transplanting, Aquilegias canadensis was transplanted from the roof to the same location and Thallactrum dolcum was transplanted from the roof to a second location to augment a woodland garden community within the forest. That same year Polomonium reptans and Viola spp., both growing profusely on the roof, began to be observed on the forest floor near the building. Although there have been only informal observation by the NCSL restoration staff, the species have shown persistence in each terrestrial location.

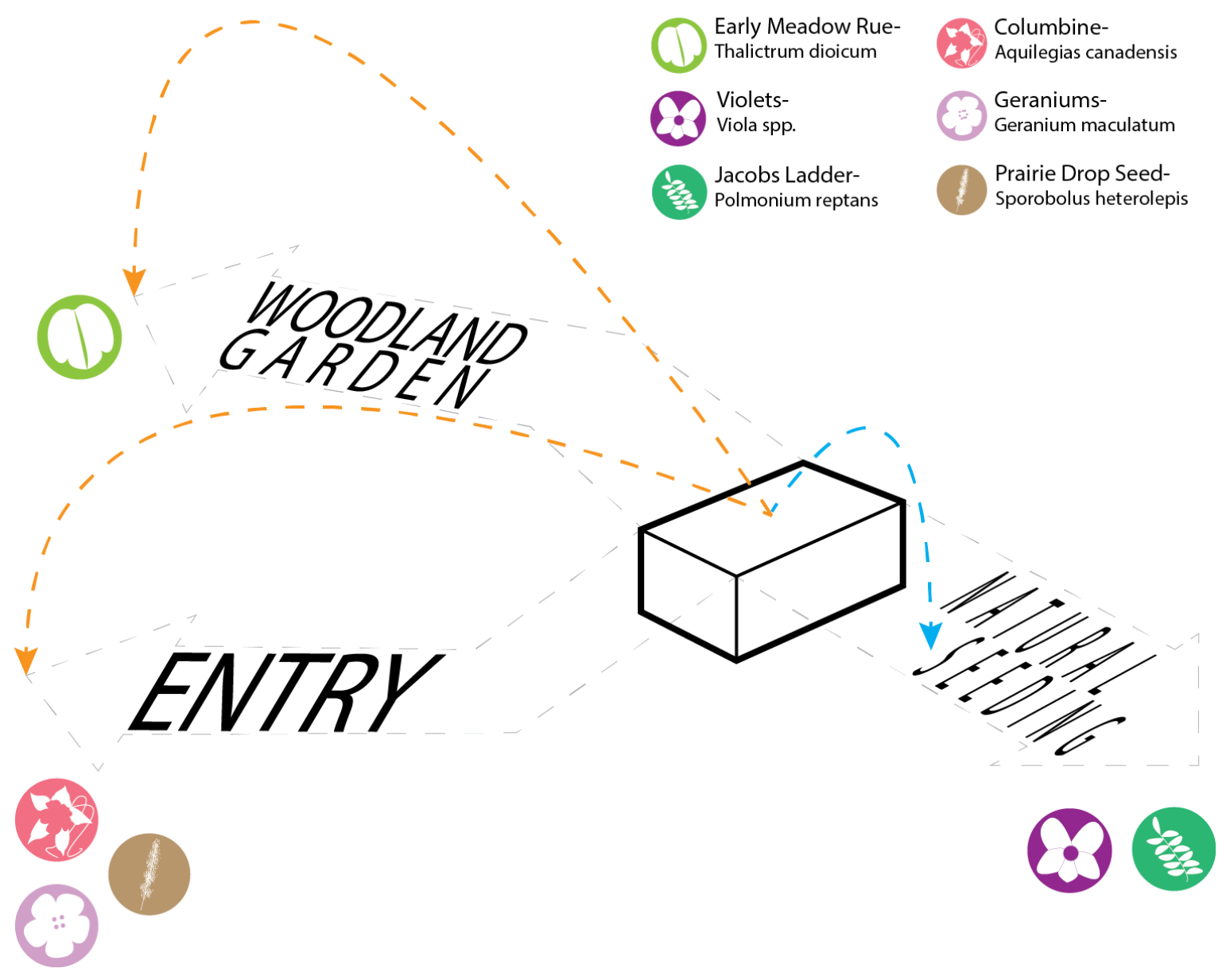

Figure 2: Diagram of the dispersal of plant species to terrestrial locations in the nature preserve. Human dispersal shown in orange and self dispersal shown in blue. 


\section{The future of nursery function and the Nature Center roof}

The observations from NCSL demonstrate vegetative roofs contribute biological materials to the terrestrial environments of cities. The dispersal activity creates the opportunity to investigate the role of nursery function in living architecture. Of course, biological community composition is influenced by spatial scales and temporal conditions (Picket and Cadenassio 1995; Tilman and Kareiva 1997), but only recently have these factors have become a part of study in green roof communities (Braaker et al 2014). In effort to contribute to community composition, we have been designing roofs within a regional context (Earthpledge 2005); and physically linking roofs to the surrounding landscape (Hopkins and Goodwin 2011), without asking ourselves "to what extent is biological material of a green roof exported to its nearby setting"?

Because two of the six species, Viola spp. and Polmonium reptans, were able to disperse on their own, we can say that some dispersal forms can act without human assistance. The other four species required humans to perform the dispersal.

To help with comprehending and communicating the concept across design and science disciplines, we would like to highlight some terminology. To begin, we offer the conceptual term terrestrial-roof link which is defined as the association of biological organisms occurring between the elevated roof and the surrounding ground plane. This term is inclusive of the current measures of community assessment, such as diversity, similarity or evenness. The linkage implies a two-way relationship in both two and three dimensional space and can be used for understanding species movement over time as well. For example, the terrestrial-roof linkage could be considered strong if there is a high degree of exchange of species, or low if only a few species interchange. Additionally, this supports the more physically derived pathways of the 'Ground-to-Roof' connections discussed by Hopkins and Goodwin (2011) and expressed in constructed projects such as Sihlpost Platform in Zurich, Switzerland (Coffman 2009).

Green roofs may function as extensions of terrestrial habitat or a simple patch within the heterogeneous urban landscape which offer additional insights into the role humans play in fostering ecosystem services. This idea can be supported by Braaker et al's (2014) study which provides an understanding of community insect assembly on vegetative roofs. They describe the importance of environmental variables of local environment, surrounding landscape, and habitat connectivity on species assembly in the invertebrate roof communities. In finding that low mobility groups, such as beetles and spiders, were more influenced by the local conditions of the roof, and that highly mobile groups, such as bees and weevils, were mainly shaped by habitat connectivity, their findings indicate differences are occurring between populations. Meanwhile, MacIvor and Lundhom (2011) found that insect communities were equally diverse as nearby terrestrial habitat and insect composition was only slightly, but not significantly different 
between the roof and ground. These studies indicate the importance of a terrestrial-roof link. It can be assumed that both unique habitat and location influence population size and dynamics. If so, to what degree do roof populations migrate? Are these patterns upheld across different kinds of taxa?

When it comes to vegetation Dunnett et al. (2008) found that colonizing plants can increase diversity of installed palettes. In a five year trial, they found the terrestrial-roof link being used by native and exotic colonizing species, common to disturbed or cultivated sites, through wind dispersal. Most were prototypical colonizers that broadened the original palette in structure and type (trees, shrubs and annuals) and a few species accounted for most of the colonizing group's abundance. The common colonizers of North America have been documented clearly with descriptions and illustrations by Snodgrass and McIntyre (2010). What is less known is 1) how the roof influences terrestrial biological activity and 2) the interaction between ecological processes and human agency. The selection of plants and the frequency of weeding are likely to be governing factors in facilitation and dispersal across the terrestrial-roof link, particularly in plants, but also in other trophic levels.

We highlight additional terminology, commonly used in the lexicon of population ecology, to assist in subsequent communication. The term agent dispersal is used when plant dispersal relies on other organisms. In the case of NCSL, four of the plant species relied on human agency for relocation from the roof to the ground. Thus, we use the term human dispersal, which is when biological dispersal relies on people. Human dispersal occurred through intentional transplantation of whole plants, or part of plants, to a new location. This was performed by NCSL staff with strategic intent to recover areas following disturbances and prevent further damage, such as path erosion control. It is traditionally used by natural resource managers who employ a wide vary of conservation techniques. The other type of dispersal observed was self dispersal which relies on dispersal strategies of the organism. The self-seeding species, Geranium and Viola spp. are both considered self dispersers because of the ejection method used to disperse their seeds.

Export will only work when the terrestrial environment is a suitable site for roof plants to colonize, and the dispersal strategy is sufficient to transport the seed or propagule to its suitable destination (which would also require compatible management, e.g., no mowing). We had a fortunate situation in the NCSL in that part of the roof area was partially shaded and thus the green roof was more similar to the forest floor than a roof fully exposed to sun. So by choosing species appropriate for that condition, all six species were more fitted for the surrounding landscape. This may have increased the probability of successful dispersal.

We advocate for further study in the terrestrial-roof connection in other locations. In our efforts to better understand how vegetative roofs provide a nursery function, we aim to record the roof plant community composition and populations of dispersed species in their terrestrial locations. 
Using the original plant scheme (Table 1) we plan to investigate the plant community and species distribution. Through further field investigations, we aim to confirm the two types of dispersal we have acknowledged here and hope to better describe and understand their impacts. We aim to better understand the population's mortality, reproduction, immigration and emigration. Equally, we aim to better uncover the factors that may be creating the roof patch to be a source, through improved documentation of current management, soil chemistry, and pollinator frequency. By further investigating each species we will be able to understand abundance, effective population size and ecological yield.

Table 1: Species installed it the green roof in 2003 (Holden Arboretum is Local and Prairie Nursery and Envirotech are regional).

\begin{tabular}{|c|c|c|c|c|}
\hline \multirow{2}{*}{ SPECIES } & \multicolumn{3}{|c|}{ CONDTIO } & \multirow[b]{2}{*}{ QUANTITY } \\
\hline & SEASON & $\mathbf{N}$ & SOURCE & \\
\hline \multicolumn{5}{|l|}{ Forbs } \\
\hline Heuchera americana & $\mathrm{n} / \mathrm{a}$ & part shade & Prairie Nursery & 36 \\
\hline Aquilegia canadensis & spring & part shade & Holden Arboretum & 18 \\
\hline Geranium maculatum & spring & part shade & Holden Arboretum & 18 \\
\hline Lupinus perennis & spring & sun & Holden Arboretum & 18 \\
\hline Polemonium reptans & spring & part shade & Holden Arboretum & 18 \\
\hline Thalictrum dioicum & spring & part shade & Prairie Nursery & 15 \\
\hline Campanula rotundifolia & summer & part shade & Prairie Nursery & 18 \\
\hline Liatris squarrosa & summer & sun & Holden Arboretum & 18 \\
\hline Silene virginica & summer & sun & Holden Arboretum & 18 \\
\hline Aster divaricatus & fall & part shade & Prairie Nursery & 18 \\
\hline Chrysopsis mariana & fall & part shade & Holden Arboretum & 18 \\
\hline Solidago flexicaulis & fall & part shade & Prairie Nursery & 18 \\
\hline \multicolumn{5}{|l|}{ Grasses } \\
\hline Carex pensylvanica & $\mathrm{n} / \mathrm{a}$ & part shade & Envirotech & 5 \\
\hline Koeleria macrantha & $\mathrm{n} / \mathrm{a}$ & sun & Holden Arboretum & 18 \\
\hline Sporobolus heterolepis & $\mathrm{n} / \mathrm{a}$ & sun & Prairie Nursery & 18 \\
\hline \multicolumn{5}{|l|}{ Ferns } \\
\hline Dennstaedtia punctilobula & $\mathrm{n} / \mathrm{a}$ & shade & Holden Arboretum & 3 \\
\hline Dryopteris marginalis & $\mathrm{n} / \mathrm{a}$ & shade & Holden Arboretum & 3 \\
\hline \multicolumn{5}{|l|}{ Sedges } \\
\hline Carex plantagenea & $\mathrm{n} / \mathrm{a}$ & shade & Holden Arboretum & 1 \\
\hline \multicolumn{5}{|l|}{ Shrubs } \\
\hline Viburnum acerifolium & & & Holden Arboretum & 1 \\
\hline Total & & & & 280 \\
\hline
\end{tabular}


It is important that future inquiry continue to investigate the breadth of ecosystem services of vegetative roofs. The current working knowledge of vegetative roofs is a result of persistent involvement from a wide range of scientific and design disciplines. Yet, disciplines such as population ecology and landscape ecology have posed few inquiries because of the rarity of roof systems for study. With greater roof prevalence, population ecologists' future participation will help expand the breadth of knowledge beyond dispersal questions as they bring new perspectives and study methodologies to the inquiry of roof technology.

Lastly, we suggest that roof design goals and stewardship practices consider biological dispersal. The idea of a roof producing biological export as a part of the original design and maintenance goals is a unique way of approaching roof conceptualization and maintenance. We believe that by perceiving vegetative roofs as a nursery source, we might begin to better link roofs to local ecosystems; prevent, or better understand unwanted dispersal such as invasive species; and unlock even more potential between the disciplines of architecture and ecology to provide ecological services within the city.

\section{Acknowledgements}

We would like to recognize Jan Zorman, past Director of Facilities at The Nature Center at Shaker Lakes, for her role in initiating the roof project and gathering us together as a group of researchers.

\section{Literature Cited}

Braaker, Sonja, Jaboury Ghazoul, Martin K. Obrist, and Marco Moretti. "Habitat connectivity shapes urban arthropod communities-the key role of green roofs." 95, no. 4 Ecology (2013) 1010-1021.

Brenneisen, Stephan. "Space for urban wildlife: designing green roofs as habitats in Switzerland." Urban Habitats 4, no. 1 (2006): 27-36.

Coffman, Reid, and Tom Waite. "Vegetated roofs as reconciled habitats: rapid assays beyond mere species counts." Urban Habitats 6, no. 1 (2010).

Coffman, Reid. "Elevating Habitat: Creating biodiversity through quasi-traditional green roof design.” Landscape Architecture Magazine, 99, no. 1, (2009) 72-77

City of Toronto, Guidelines for biodiverse green roofs accessed June 5, 2014 https://www1.toronto.ca/City\%200f\%20Toronto/City\%20Planning/Zoning\%20\&\%20En vironment/Files/pdf/B/biodiversegreenroofs_2013.pdf

Earth Pledge Organization. Green roofs: ecological design and construction. Schiffer Pub Limited, 2005. 
Grant, Gary. "Extensive green roofs in London." Urban Habitats 4, no. 1 (2006): 51-65.

Hopkins, Graeme, and Christine Goodwin. Living architecture: green roofs and walls. CSIRO Pub., 2011.

Felson, Alexander J., and Steward TA Pickett. "Designed experiments: new approaches to studying urban ecosystems." Frontiers in Ecology and the Environment 3, no. 10 (2005): 549-556.

MacIvor, J. Scott, and Jeremy Lundholm. "Insect species composition and diversity on intensive green roofs and adjacent level-ground habitats." Urban ecosystems 14, no. 2 (2011): 225241.

Meffe, Gary K., and Carroll, Carl Ronald. Principles of conservation biology. Sunderland: Sinauer Associates, 1996.

Mostafavi, Mohsen and Gareth Doherty, eds. Ecological urbanism. Baden: Lars Müller Publishers, 2010.

Oberndorfer, Erica, Jeremy Lundholm, Brad Bass, Reid R. Coffman, Hitesh Doshi, Nigel Dunnett, Stuart Gaffin, Manfred Köhler, Karen KY Liu, and Bradley Rowe. "Green roofs as urban ecosystems: ecological structures, functions, and services." BioScience 57, no. 10 (2007): 823-833.

Osmundson, Theodore. Roof gardens: history, design, and construction. WW Norton \& Company, 1999.

Pickett, Steward TA, M. L. Cadenasso, and Brian McGrath. Resilience in Ecology and Urban Design. Springer Science + Business, 2013

Rowe, D. Bradley. "Green roofs as a means of pollution abatement." Environmental Pollution 159, no. 8 (2011): 2100-2110

Tilman, David, and Peter M. Kareiva, eds. Spatial ecology: the role of space in population dynamics and interspecific interactions. Vol. 30. Princeton University Press, 1997.

Waldheim, Charles, ed. The landscape urbanism reader. Princeton Architectural Press, 2006.

Wolf, Derek, and Jeremy T. Lundholm. "Water uptake in green roof microcosms: Effects of plant species and water availability." Ecological Engineering 33, no. 2 (2008): 179-186. 